\title{
Estimation of thermal resistance field in multilayer materials by autoregressive asymptotic method calibrated with analytical quadrupole method
}

\author{
by M. Bensalem*, A. Sommier ${ }^{\star \star}$, E. Abisset**, S. Chevalier**, J.L. Battaglia**, J.C. Batsale ${ }^{\star \star}$ and \\ C. Pradere ${ }^{\star *}$
}

\begin{abstract}
* Epsilon company, esplanade des arts et métiers, 33405 Talence cedex, mbensalem@epsilon-alcen.com
** I2M Institute, UMR CNRS 5295, esplanade des arts et métiers, 33405 Talence cedex, alain.sommier@ubordeaux.fr, emmanuelle.abisset-chavanne@ensam.eu stephane.chevalier@u-bordeaux.fr, jean-luc.battaglia@ubordeaux.fr, jean-christophe.batsale@u-bordeaux.fr and christophe.pradere@u-bordeaux.fr
\end{abstract}

\begin{abstract}
This paper addresses the problem of the quantitative estimation of thermal resistance fields in multilayer material by using a flash excitation and an IR camera for the temperature relative change measurement. The main difficulty that arises with multilayer materials affected by thermal resistances as delamination, crack or rugosity is related to the inverse processing method. Indeed, it is shown that the method has to be based on an iterative algorithm in order to quantitatively retrieve the thermal resistance. Moreover techniques based on Thermal Signal Reconstruction [1, 2] which presents the advantage to easily use the measured field are not especially quantitative and generally only address the detection of such defects in a qualitative way. Some authors [3,4] have proposed original approaches to retrieve quantitative analysis. In the present study, the main idea is to link a simple method based on an asymptotic development of the thermal contrast with an exact modelling of the heat transfer within the multilayer material. The asymptotic method consists in a first order differential equation between a reference temperature, taken directly in a healthy area of the sample or resulting from the exact analytical solution of the multilayer sample, and a temperature that is assumed to be at a location affected by a thermal resistance problem, as showed by eq (1). The asymptotic development reveals two parameters: the amplitude $\mathrm{A}$ and a delay $\tau$ that could be linked to the thermal resistance value and related defect thickness thanks to the analytical model.
\end{abstract}

$$
T\left(x_{i}, y_{i}, t\right)=A T\left(x_{r e f}, y_{r e f}, t\right)+\tau \frac{d T\left(x_{r e f}, y_{r e f}, t\right)}{d t}
$$

The exact 1D transient analytical solution is calculated using multilayer quadrupole [5] where only one interface layer is considered as a thermal resistance. The temperature response is then calculated from a given range of thermal resistance (figure 1.b). In this case, the range goes from $10^{-2}$ to $4.10^{-2} \mathrm{~K}^{\mathrm{m}} \mathrm{m}^{2} \mathrm{~W}^{-1}$. From this set of data, the inverse method, based on equation (1), is implemented and the estimated parameters $A$ and $\tau$ are calibrated as function of the imposed thermal resistance value (figure 1.c). Then with this calibrated curve (generally polynomial), experimental processing can be done by assuming that the sample has the same multilayer assembly that the analytical one. The inverse method consists in an autoregressive approaches along time. This part will be discussed in the paper.

Finally, to illustrate the complete process a homemade sample composed of a black painted thin layer ( $25 \mu \mathrm{m})$ of steel, a PVC with several square hole of different thickness $(100,200,500$ and $800 \mu \mathrm{m})$ and depth $(1100,1000,700$ and 400 $\mu \mathrm{m})$, and a last layer thick layer of steel $(3 \mathrm{~mm})$ was tested by using a $1600 \mathrm{~J}$ flash lamp and a MCT IR camera. The results of the several steps of the method are presented figure 1 . It is interesting to note that it is possible to retrieve quantitative in depth thermal resistance by using very fast and simple inverse processing based on asymptotic development coupled with a complete quantitative calibration.

\section{REFERENCES}

[1] Shepard SM, Ahmed T, Rubadeux BA, Wang D, Lhota JR. Synthetic processing of pulsed thermographic data for inspection of turbine components. Insight. 2001;43(9):587-589.

[2] Balageas D. Thickness or diffusivity measurements from front-face flash experiments using the TSR (thermographic signal reconstruction) approach. Conférence QIRT 2010, Quebec, Canada, 27-30 Juill. 2010. Papier QIRT 2010-011. Available on QIRT Open Archives: http://dx.doi.org/10.21611/qirt.2010.011.

[3] Oswald-Tranta, B., Maier, A. \& Schledjewski, R. Defect depth determination in a cfrp structure using tsi technique. The 12 (2014). 
[4] Feuillet, V., Ibos, L., Fois, M., Dumoulin, J. \& Candau, Y. Defect detection and characterization in composite materials using square pulse thermography coupled with singular value decomposition analysis and thermal quadrupole modeling. NDT \& E International 51, 58-67 (2012).

[5] D. Maillet, S. André, J.-C. Batsale, A. Degiovanni, C. Moyne, Thermal Quadrupoles: Solving the Heat Equation through Integral Transforms. John Wiley and Sons, New-York, 2000.

a)

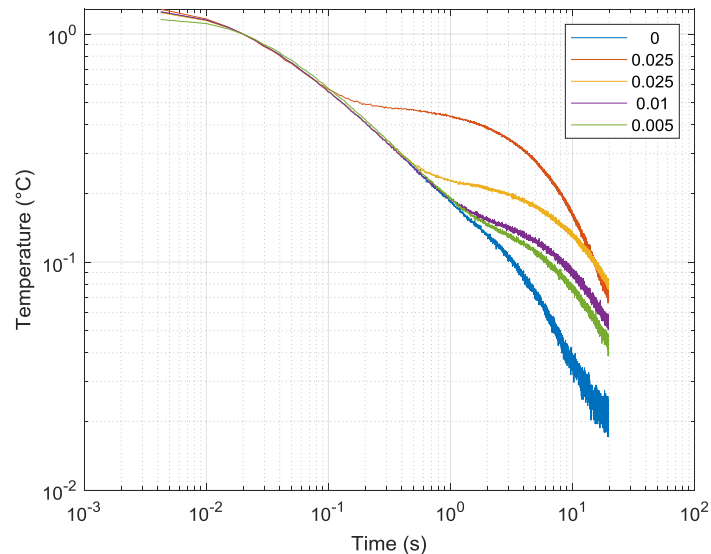

$\left.{ }^{2} \mathrm{C}\right)$

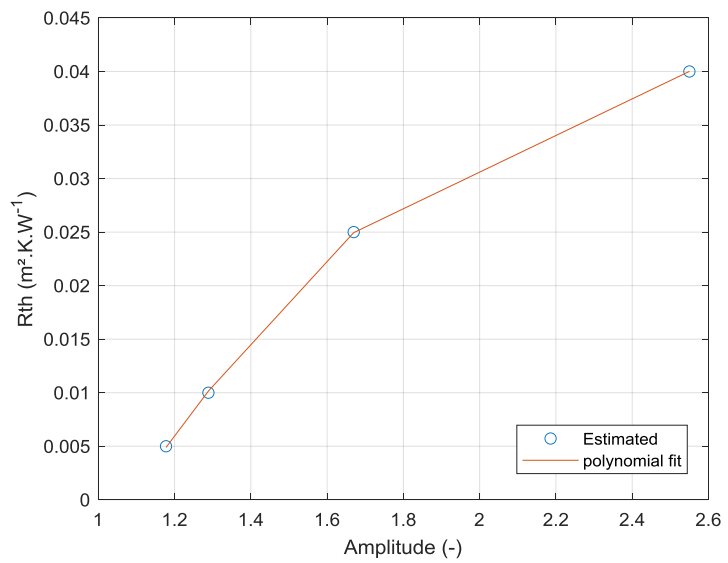

b)

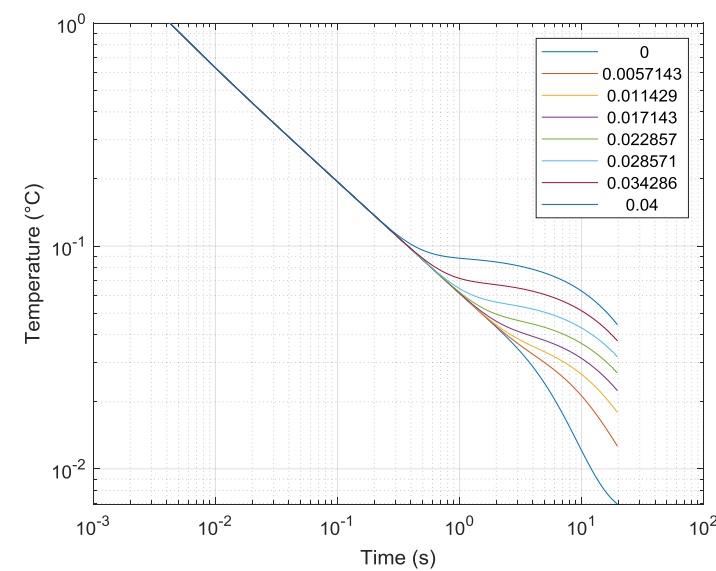

d)

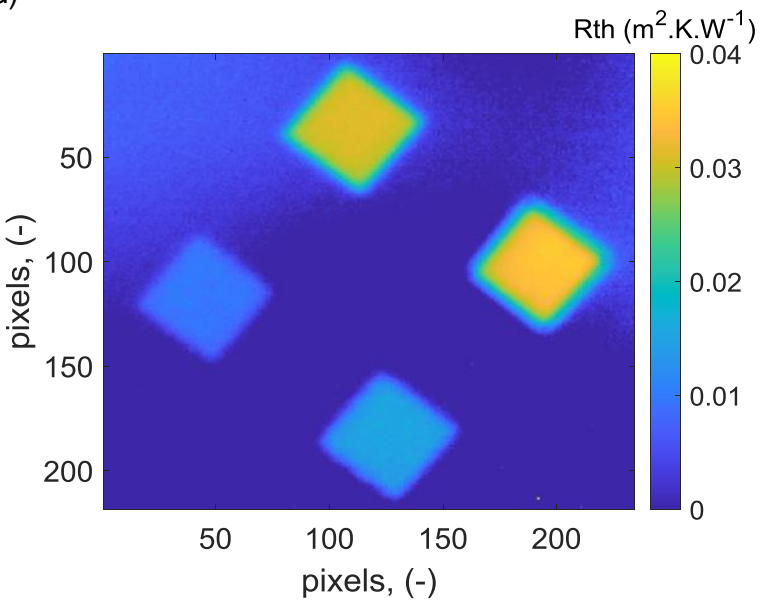

Fig. 1. Presentation of some results on a multilayer homemade sample: a), Front face measured thermogram at several location, b) example of calculated thermogram from the quadrupole method for several thickness and thermal resistance, c), calibration curve of the well-known simulated thermal resistance as function of the estimated amplitude $A$, and $d$ ), resulting thermal resistance from the calibration curve $c$ ). 